\title{
Children's Feedback Preferences in Response to an Experimentally Manipulated Peer Evaluation Outcome: The Role of Depressive Symptoms
}

\author{
Albert Reijntjes • Maja Dekovic • Marjolijn Vermande • \\ Michael J. Telch
}

Published online: 6 February 2007

(C) Springer Science+Business Media, LLC 2007

\begin{abstract}
The present study examined the linkage between pre-adolescent children's depressive symptoms and their preferences for receiving positive vs. negative feedback subsequent to being faced with an experimentally manipulated peer evaluation outcome in real time. Participants $(n=142)$ ages 10 to 13 , played a computer contest based on the television show Survivor and were randomized to either a peer rejection (i.e., receiving the lowest total 'likeability' score from a group of peer-judges), a peer success (i.e., receiving the highest score), or a control peer evaluation condition. Children's self-reported feedback preferences were then assessed. Results revealed that participants assigned to the negative evaluation outcome, relative to either the success or the control outcome, showed a significantly higher subsequent preference for negatively tuned feedback. Contrary to previous work and predictions derived from selfverification theory, children higher in depressive symptoms were only more likely to prefer negative feedback in response to the negative peer evaluation outcome. These effects for depression were not accounted for by either state mood at baseline or mood change in response to the feedback manipulation.
\end{abstract}

\footnotetext{
A. Reijntjes · M. Dekovic $\cdot$ M. Vermande

Utrecht University,

The Netherlands

M. J. Telch

University of Texas at Austin,

Austin, TX, USA

\section{A. Reijntjes $(\square)$}

Department of Psychosocial Development in Context,

Utrecht University,

P.O. Box 80150, The Netherlands

e-mail: a.h.a.reijntjes@fss.uu.nl
}

Keywords Peers $\cdot$ Feedback preferences $\cdot$ Pre-adolescent children $\cdot$ Depressive symptoms $\cdot$ Sociometric status

Depression is a leading cause of disability across the life span (Murray \& Lopez, 1996). Whereas the point prevalence of major depressive disorder (MDD) in school-age children is relatively modest (i.e., between 1 and 3 percent; Cohen et al., 1993), epidemiological community surveys of childhood disorders suggest that 10 to 20 percent of school-aged children in the general population experience periods of elevated depressive symptoms, including depressed mood (e.g., Compas, 1997; Hammen \& Rudolph, 1996). Several studies have shown that moderate levels of depression are associated with significant impairment in school and peer functioning (e.g., Nolen-Hoeksema, Girgus, \& Seligman, 1992; Petersen, Sarigiani, \& Kennedy, 1991), and may persist for years in some children (Nolen-Hoeksema et al., 1992). Moreover, children displaying moderate levels of depressive symptoms are at high risk to suffer from severe, recurrent major depression later in life (e.g., Costello, Angold, \& Keeler, 1999; Lewinsohn, Rohde, Klein, \& Seeley, 1999). Taken together, although moderate levels of depressive symptoms may not meet DSM-IV-TR (APA, 2000) criteria for MDD, they are of significant concern.

Several theorists have argued that feedback seeking may be implicated in the maintenance and/or exacerbation of dysphoric states, including the development of full-blown depression. For instance, Coyne (1976) has asserted that people high in depression systematically alienate their relationship partners through excessive reassurance seeking. This behavior is particularly likely to elicit negative reactions in others-including rejection, raising the risk of becoming even more depressed-when people's feedback seeking reflects their suspicion that they will not receive such 
reassurance (e.g., constantly asking their partners if they still love them).

Whereas Coyne suggested that depressed people merely inadvertently create the social conditions that make them suffer, the more recently advanced self-verification theory (e.g., Swann, 1990; Swann, Rentfrow, \& Guinn, 2002) posits that people high in depression seek out negative social feedback more actively, as a means of verifying their negative self-conceptions. Specifically, according to self-verification theory (e.g., Swann, 1983; Swann, Pelham, \& Krull, 1989; Swann, Rentfrow, \& Guinn, 2002) individuals are drawn to feedback that confirms their self-conceptions because it tends to buttress their feelings of existential security ("epistemic" concerns) and/or because they want their social interactions to unfold smoothly, and thus work to ensure that others do not form appraisals of them that are overly positive or overly negative ("pragmatic" concerns).

Negative self-views including worthlessness, repulsiveness, and excessive self-criticism figure prominently in depression (e.g., Beck, 1967; Ellis, 1977). Consistent with self-verification theory, several studies among adults have provided evidence to suggest that people higher in depression are more inclined to actively seek out (or prefer) negative social feedback, as well as interaction partners likely to provide them with such unfavorable feedback. For instance, Swann and colleagues observed that depressed college students, relative to controls, preferred friends who evaluated them negatively, were more inclined to seek negative feedback from their roommates, and preferentially solicited unfavorable feedback from their dating partners (Swann, Wenzlaff, Krull, \& Pelham, 1992). Moreover, when presented with self-discrepant (i.e., positive) feedback, adults high on depressive symptoms appeared to attempt to restore their sense of worthlessness by subsequently seeking feedback about their weaknesses from a different evaluator; whereas adults low on depressive symptoms were more likely to solicit feedback about their strengths (Swann, Wenzlaff, $\&$ Tafarodi, 1992). Finally, participants higher on depressive symptoms, relative to controls, were more likely to choose interacting with someone who appraised them negatively over the opportunity to avoid the encounter (Swann et al., 1992).

Contrary to research with adults, the investigation of how depression in children is associated with feedback seeking preferences is still in its infancy. Joiner and colleagues (Joiner, Katz, \& Lew, 1997) examined the linkage between depression and feedback seeking in a sample of inpatient youths. They found that children who were more depressed showed a greater preference for receiving feedback of a negative nature, based on responses to a questionnaire assessing feedback preferences in four distinct self-relevant domains (i.e., social, intellectual, athletic, and physical attractiveness). As noted by the authors, an important limitation of this study was the unknown predictive validity of their feedback preference questionnaire. Hence, it is unclear to what extent scores on this measure converge with participants' actual preference for negative feedback in the face of actually occurring events (see Joiner et al., 1997).

In the only study to examine feedback seeking in children using a community sample, Cassidy and colleagues used a bogus feedback paradigm to examine children's actual feedback preferences (Cassidy, Ziv, Mehta, \& Feeney, 2003). Specifically, participants provided personal information about themselves by completing a series of questionnaires. They were led to believe that their responses would be shown to peers from a different school who would use this information to answer specific questions of an evaluative nature about each participant. Next, participants were provided the opportunity to select some of the alleged answers to these questions, knowing that some answers would include negative feedback and others would include positive feedback. In line with findings for adults and children diagnosed with depression, children displaying higher depressive symptoms were more likely to display a relative preference for negative information about themselves. A similar pattern of findings consistent with self-verification theory was observed for the linkage between feedback preferences and global self-representations, as indexed by level of general self-esteem.

An important contribution of the Cassidy et al. study is that it provides evidence to suggest that the tendency for depressed individuals to prefer rather negative feedback extends to moderately depressed children and adolescents, as indexed by level of self-reported depressive symptoms. However, the study is limited by its relatively narrow scope of inquiry with regard to the role of depressive symptoms. First, the potential role of state mood was not examined. Whereas self-verification theory claims that interest in negative feedback is motivated by negative self-views, an alternative explanation for the linkage between elevated depressive symptoms and more negative feedback preferences is that due to high levels of depressed state mood, people displaying elevated depressive symptoms are prone to be drawn to all that is negative, including unfavorable appraisals from others (e.g., Beck, 1967; Beck, Rush, Shaw, \& Emery, 1979). Moreover, enhancing state mood with adults by providing them with experimentally manipulated favorable evaluations has been shown to increase levels of subsequent positive feedback seeking (Mischel, Ebbesen, \& Zeiss, 1973).

A second limitation of the Casssidy et al. study is that the valence of the evaluative feedback was not manipulated. Beck has asserted that depressed people seek unfavourable feedback only insofar as their negative self-views have been activated by a stressful negative event. Work conducted by Swann and colleagues (Swann et al., 1992) has shown that adults high in depressive symptoms respond quite 
differently with respect to their feedback preferences in the face of positive, negative, or neutral evaluations. Specifically, these individuals responded to positive-i.e., selfdiscrepant-evaluations with a more pronounced preference for negatively tuned feedback, relative to a control condition; whereas they were not more inclined to seek negative feedback subsequent to receiving unfavorable-i.e., selfcongruent-evaluations.

The present study examined the linkage in pre-adolescent children between depressive symptoms and feedback preferences, in response to a salient and ego-involving emotioneliciting event. Specifically, we examined these linkages in response to both a positive and a negative peer evaluation outcome. We chose peer evaluation as the emotion provocation stimulus because peer praise and peer rejection are common emotion-eliciting events in childhood (Coie, 1990). Moreover, ample evidence suggests that rejection ranks among the most aversive of human experiences and is associated with marked negative affect (e.g., Baumeister \& Tice, 1990; Leary, Tambor, Terdal, \& Downs, 1995). Finally, peer rejection figures prominently in the development and/or maintenance of several forms of psychopathology, including depression (e.g., Nolan, Flynn, \& Garber, 2003). The reason for our focus on pre-adolescent children is twofold. First, the most salient content of self-representations among preadolescents is one's social appeal and social skills/attributes that influence interactions with others (Harter, 1998). Second, in this age group approximtely 50\% of children's social activities involve peers (Grusec \& Lytton, 1988; Rubin, Bukowski, \& Parker, 1998), and peers as a reference group are of central importance in these children's lives (e.g., Hay, Payne, \& Chadwick, 2004; Hartup, 1996).

Toward this aim, we devised an experimental peer evaluation manipulation based on the television show Survivor. In brief, participants were led to believe that they were playing an Internet version of Survivor against four same-sex contestants of comparable age (all of them were computerized bogus contestants) from four different schools in the same area. They were informed that a team of 16 same-age peer judges consisting of eight boys and eight girls would evaluate all participants. Specifically, each juror would give them a score between 0 and 100 , with higher scores reflecting higher levels of perceived likeability. Moreover, the jurors would indicate what they liked most and what they disliked most about each contestant. Participants were randomized to one of the following three peer evaluation feedback conditions: (a) success feedback (i.e., having obtained the highest total score), (b) failure feedback (i.e., having obtained the lowest total score), or (c) control feedback (i.e., having obtained neither the highest nor the lowest score). These feedback conditions were designed to induce mood improvement, mood worsening, and no mood change, respectively. Subsequent to receiving the bogus peer evaluation feedback outcome, chil- dren's feedback preferences were assessed. The assessment of state mood at pre- and post-feedback afforded the possibility to examine the linkages between participants' level of depressive symptoms, feedback valence, (changes in) state mood, and subsequent feedback preferences. To increase the specificity of our findings for depressive symptoms, we also examined the potential role of children's peer-nominated social standing in affecting their feedback preferences.

In sum, the present study aimed to address the following specific research questions: (a) Does the type (valence) of peer feedback influence children's subsequent feedback preferences? (b) Are the effects of feedback valence moderated by children's level of depressive symptoms? (c) Do differences in state mood at baseline account for these potential effects of depression? and (d) Are the effects of feedback valence and depressive symptoms on subsequent feedback seeking mediated by changes in mood from pre to postfeedback?

We hypothesized that children assigned to receive a positive peer evaluation outcome would be more likely to prefer subsequent favorable feedback than those assigned to the neutral peer feedback condition; whereas children assigned to receive a negative peer evaluation outcome would not be more likely to prefer subsequent negative feedback. This set of predictions was based on findings with adults suggesting that positively valenced feedback leads to a subsequent preference for positively tuned feedback (Mischel et al., 1973), whereas Swann and colleagues (Swann et al., 1992) found that negative feedback exerted no effect on adults' subsequent preference for negative feedback. We also hypothesized that level of depressive symptoms would qualify the relationship between our peer feedback manipulation and children's subsequent feedback preferences, such that children higher on depressive symptoms would be more likely to respond to positive-i.e., self-discrepant—evaluations with a preference for negatively tuned feedback, relative to the control condition. Finally, we hypothesized that the effects of the peer feedback manipulation on subsequent feedback preferences would be mediated by changes in state mood from pre- to post-feedback.

\section{Method}

Participants

Participants were 142 children ( 73 boys, 69 girls) enrolled in 5th and 6th grade classes from two public elementary schools in the Netherlands. They were predominantly Caucasian $(92.9 \%)$, ranged in age from 10 to 13 years $(M=11.2$, $S D=.66$ ) and were predominantly from a middle-class SES background. For the initial sample of 185 children, classroom teachers sent parent permission letters home with children. 
Of the 165 letters returned, 142 parents $(86.1 \%)$ gave their consent for their children to participate in the study, and $23(13.9 \%)$ declined. We also obtained verbal permission to perform the study from the principal of the school and each child's teacher. Children were informed that they could discontinue their participation at any time.

\section{Procedure}

In the first of two sessions, approximately one week apart, participants were administered the Children Depression Inventory (CDI, Kovacs, 1981) in their regular classrooms during school hours. Moreover, participants' social standing in their peer group was assessed via a commonly used procedure, which asks children to indicate whom among their classmates they like most and whom they like least (e.g., Newcomb, Bukowski, \& Pattee, 1993). During administration of the measures the classroom teacher remained in the room. A research assistant read the directions aloud and children were encouraged to ask for help if they had questions or encountered problems completing the questionnaires. At the end of the first session, which lasted approximately $30 \mathrm{~min}$, children were informed that later that week they would participate in a computer-contest. The second session was carried out in a quiet room on the school grounds. Participants were told that their class was selected to take part in an Internet computer-contest called 'Survivor.' In reality, the contest was a computer program written in Visual Basic designed to present the illusion of playing on-line with four other children.

\section{Survivor contest}

Upon arrival, the participant was seated in front of a laptop computer equipped with a web-cam to have their photo taken. Participants were told that their picture would allow all the contestants to see what each of the other children looked like. Prior to beginning (Time 1), participants completed a computer-administered baseline mood measure, i.e., a oneitem mood scale ranging from 1 (extremely negative) to 10 (extremely positive). In an attempt to add both to the credibility and the attractiveness of the contest, the opening bars of the hit 'Survivor' (produced by the band "Destiny's Child") were played at the start of the game. In addition, an eye-catching logo of the American TV-show appeared on the computer display.

The objective and rules of the contest were presented on screen. Participants were encouraged to read the information, which was pre-tested on comprehensibility for children in this age-range, carefully in their own pace and click "continue" to progress to the next screen. Participants were informed that they would be playing against four same-sex contestants of comparable age (all of them were computerized fictitious co-players) from four different schools in the same area, and that all participants would be evaluated by a jury consisting of 16 members, eight boys and eight girls. Specifically, participants were explained that each judge would give them a score between 0 and 100, with higher scores reflecting higher levels of perceived likeability.

After receiving this information, the computer displayed a screen announcing that in a moment pictures and names of all 16 judges would be presented one-at-a-time. The children whose pictures appeared were child actors from two different modeling agencies in the Netherlands. In a pilot study, 31 adults rated the attractiveness of 43 children's faces, (20 boys, 23 girls) on a scale ranging from 1 (extremely unattractive) to 10 (extremely attractive). For the purposes of the present study, we selected the eight children rated highest (four boys, $M=7.9$, and four girls, $M=8.1$ ) and the eight children rated lowest (four boys, $M=5.2$, and four girls, $M=5.1$ ). Following the viewing of these children, participants were directed through a series of screens in which they were asked to answer a series of questions that would give the members of the jury and the other contestants information about them. Participants responded to questions about their favorite musical group, hobbies, future occupation, things they liked and disliked about themselves, a number of character traits (e.g., sense of humor, agreeableness, intelligence, trustworthiness), how they got along with other children, and their academic performance. Most of the questions were in a multiple-choice format but some (e.g., "what is your favorite musical group?") required an openended response. In view of the potential risk that children would respond to personal questions in a socially desirable fashion, instructions emphasized the importance of responding to questions honestly. To further minimize response bias, most questions were worded such that the "best" or "optimal" answer was unclear (e.g., "what is your favorite leisure activity"?). Participants were informed on screen that their picture (previously taken by a web camera) along with the biographical information from their answers to the personal questions would be transmitted over the Internet and viewed by the judges who would then give them a 'likeability' score ranging from 0 to 100 . Moreover, children were informed that the judges would also indicate what they liked most and what they disliked most of each participant (e.g., "(s)he doesn't seem to be a nice person," "(s)he is witty," "(s)he is unattractive," "(s)he seems fun to hang out with").

Subsequent to answering all the biographical questions, participants were informed that pictures and descriptions of each of the other contestants would be presented one-at-atime for review. Upon clicking "continue," the picture of the first bogus co-player was displayed together with his or her self-description. The latter consisted of the alleged answers to the same questions that the participant had answered earlier. To enhance credibility of the bogus co-players, 
actual self-descriptions were taken from those of same-age children participating in another study. These participants gave their explicit consent to have this information viewed by other children, provided that the alleged self-description profiles would contain randomly combined personal information from at least three different children. Participants progressed through the game examining each of the profiles at their own pace.

Following the participant scrutinizing the last profile, a message appeared on the screen indicating that the computer would now for every player add the scores from the judges to determine which player had received the highest total score and which player had received the lowest total score. After a $5 \mathrm{~s}$ waiting period, the names of the players with the highest and the lowest score appeared in capital letters on the screen. In the success condition, the name of the participant was displayed as having obtained the highest total score; one randomly chosen alleged co-player's name appeared as having obtained the lowest total score. Conversely, in the failure condition the name of the participant was displayed as having obtained the lowest total score, while one alleged co-player's name appeared as having obtained the highest total score. In the control condition, the participant received neither the highest nor the lowest score.

Five seconds after receiving feedback (Time 2), participants were re-administered the mood measure via computer. Instructions emphasized the importance of rating how they felt 'right now.' Subsequent to completing this measure, participants were administered the feedback measure which assessed preferences for obtaining feedback from jurors that had evaluated them favorably versus jurors that had evaluated them unfavorably. Subsequently, a computer screen appeared announcing that children would now participate in another study. The participant was then accompanied to an adjacent room where a female research assistant debriefed him or her thoroughly.

\section{Debriefing}

Each child was thoroughly debriefed with the aim of removing any lingering effects of the false rejection feedback while participating in the Survivor contest. During the debriefing, the child was informed that the judges, the co-players and the received feedback were entirely fictitious and that this deception was a necessary part of the procedure. At this point it should be noted that in our previous work, more than 100 participants were assigned to receive Survivor-administered peer rejection feedback (Reijntjes et al., 2006), including children with elevated depressive symptoms. Interviews with all participants, both immediately post-feedback as well as at one-week follow-up, indicated that the peer failure experience was not too emotionally upsetting. For instance, when asked, none of the participants made mention of any feelings of regret with regard to participation and none reported any objections to the procedure. On the contrary, several children-spontaneously-reported to consider the rejection experience an unnerving but useful experience, for themselves and/or their peers. Still, during the investigation a registered clinical psychologist was available when needed. Moreover, before being dismissed children were interviewed at length about a recent positive social experience in which they felt positive and/or were successful. In so doing, we aimed to maximize the remedy for children showing a strong emotional response to the peer feedback.

Towards the end of the debriefing, participants were encouraged to ask questions or voice their concerns. All children reported that they understood the purposes of the research, as well as the necessity of having been deceived. The credibility of the deception manipulation was also assessed during the debriefing by asking each participant whether they had believed that they were playing against other children. With no exception, participants indicated that they believed that the game was genuine. Finally, all participants reported that prior to participating they had not talked with classmates about Survivor. At the conclusion of the debriefing, participants were urged to observe complete secrecy by not talking with their classmates about Survivor until all the other children had participated. To increase adherence to this instruction, children were asked to sign a non-disclosure agreement and were then provided a choice of one of several possible small gifts for playing the game (e.g., a small tape recorder, a gift certificate worth about 3 dollars).

\section{Measures}

\section{State mood}

Similar to previous work among children (Reijntjes, Stegge, Meerum Terwogt, Kamphuis, \& Telch, 2006) and adults (e.g., Gross, 1998), children rated their current feeling state using a one-item global mood index, ranging from 1 (extremely negative) to 10 (extremely positive). This Likertscale was administered to assess participants' state mood at baseline (pre-feedback), and their changes in state mood from pre- to post-feedback. The mean score at baseline was $7.96(S D=1.36)$. Scores did not differ as a function of age, gender, or their interaction.

\section{Children Depression inventory (CDI; Kovacs, 1981)}

The CDI is a 27-item self-report measure designed to assess the social, behavioral, and affective symptoms of depression in children. Each item consists of three sentences that describe a symptom of depression in increasing degrees of severity. The respondent chooses the sentence that best describes him or her during the past week. Each item set is 
scored from 0 (symptom absent) to 2 (symptom is present always or most of the time). The CDI has adequate discriminant and convergent validity, test-retest reliability, and internal consistency (Saylor, Finch, Spirito, \& Bennett, 1984). Coefficient alpha in the present sample, using the Dutch version of the instrument (Braet \& Timbremont, 2002), was .80. Total scores ranged from 0 to 23 ; the median is 6 . The top quartile (i.e., $24.6 \%$ of the participants) obtained a score of 12 or higher. Eleven participants $(7.7 \%)$ obtained a score of 20 or higher, which is recommended as a cut-off point for general screening (Kovacs, 1992). Mean scores of this sample ( $M=8.03, S D=6.59)$ were similar to those previously reported (Reijntjes et al., 2006; Smucker, Craighead, Craighead, \& Green, 1986) and did not differ as a function of age, gender, or their interaction.

\section{Social standing in the peer group}

Participants completed a widely used nomination-based sociometric questionnaire, in which they identified the three classroom peers whom they liked most and the three classroom peers they disliked most (Newcomb et al., 1993). Children who declined participation in the present study were included in the classroom lists, however the data collected on these children were not used. From these nomination data, two continuous scores for each participating child were computed. These scores included: (a) a measure of preference, by dividing the number of times each participant was nominated for the 'like most' question by the total number of participating children in the class, and (b) a measure of rejection, by dividing the number of times each participant was nominated for the 'like least' question by the total number of participating children in the class. Our measure of social acceptance (i.e., social standing in the peer group) was computed by subtracting the measure of rejection from the measure of preference. This figure was then multiplied by 100 , yielding scores ranging from -84.6 to $61.5(M=3.56$; $S D=27.10)$. These scores did not differ as a function of gender, age, or their interaction. For the majority of participants (58\%), a positive social acceptance score was observed. Based on the widely used taxonomy for sociometric classification (Newcomb et al., 1993), the number of children that were classified as "popular," "rejected," "neglected," "controversial," and "average" amounted to $26,26,24,8$, and 58, respectively.

Table 1 Means and standard deviations of baseline measures by condition

\section{Self- reported feedback preference}

Subsequent to receiving the bogus peer evaluation outcome, participants responded to the measure assessing the valence of feedback preferences (i.e., positive versus negative). The specific dichotomous probe included: 'Which judges would you prefer to get feedback from, those that hold a positive view on you or those that hold a negative view on you'?

\section{Results}

Preliminary analyses

Exploratory analyses revealed a departure from symmetry for the distribution of the CDI, as evidenced by a skewness value of 5.84. We therefore performed a square root transformation on the scores, which was successful in producing a distribution that was no longer skewed (skewness value is .73). This transformed variable $\left(\mathrm{CDI}_{\mathrm{t}}\right)$ was used in all analyses reported below. Participants reporting higher $\mathrm{CDI}_{\mathrm{t}}$ scores displayed lower levels of state mood at baseline $(r=-.26$, $p<.01)$. Moreover, higher $\mathrm{CDI}_{\mathrm{t}}$ scores were negatively associated with peer nominated social acceptance ratings $(r=-.21, p<.02)$.

\section{Equivalence of the experimental groups}

Children were matched on age and gender, and then randomly assigned to one of the three experimental conditions. Means and standard deviations for Time 1 measures are presented in Table 1. To confirm that the randomization procedure resulted in comparable groups, baseline differences on continuous measures were examined using one-way ANOVAs. Results revealed no significant between-group differences.

Change in state mood: Effects of the feedback manipulation

Means and standard deviations for state mood scores at Time 1 (baseline) and Time 2 (immediately post-feedback) are presented in Table 2. Two a priori repeated measures ANOVA's were performed to examine the magnitude and direction of emotional reactivity elicited by success feedback and failure feedback, each relative to the control (neutral) feedback

\begin{tabular}{|c|c|c|c|c|c|c|}
\hline \multirow[b]{3}{*}{ Measure } & \multicolumn{6}{|c|}{ Feedback condition } \\
\hline & \multicolumn{2}{|c|}{ Success $(n=47)$} & \multicolumn{2}{|c|}{ Neutral $(n=47)$} & \multicolumn{2}{|c|}{ Failure $(n=45)$} \\
\hline & $\bar{M}$ & $S D$ & $\bar{M}$ & $S D$ & $\bar{M}$ & $S D$ \\
\hline Depressive symptoms & 7.83 & 7.18 & 8.34 & 6.78 & 8.11 & 6.00 \\
\hline Social acceptance & 3.72 & 27.47 & 3.90 & 27.63 & 3.02 & 26.75 \\
\hline Age (months) & 134.62 & 8.22 & 134.17 & 8.11 & 132.38 & 7.52 \\
\hline
\end{tabular}


Table 2 Means and standard deviations for state mood at baseline (Time 1 ) and immediately post feedback (Time 2 ) by condition

\begin{tabular}{|c|c|c|c|c|c|c|}
\hline & \multicolumn{6}{|c|}{ Feedback condition } \\
\hline & \multicolumn{2}{|c|}{ Success $(n=46)$} & \multicolumn{2}{|c|}{ Neutral $(n=45)$} & \multicolumn{2}{|c|}{ Failure $(n=42)$} \\
\hline & $\bar{M}$ & $S D$ & $\bar{M}$ & $S D$ & $\bar{M}$ & $S D$ \\
\hline Time 1 & 7.83 & 1.52 & 8.03 & 1.08 & 8.02 & 1.47 \\
\hline Time 2 & 8.83 & 1.25 & 8.19 & 1.19 & 6.84 & 2.05 \\
\hline
\end{tabular}

Note. Due to technical failures, data were not collected for 6 participants (1 randomized to the success condition, 2 to the neutral condition, and 3 to the failure condition).

condition. In the first planned contrast, state mood scores at Time 1 and Time 2 served as the dependent variables. Condition (Success vs. Neutral feedback) served as the between subjects factor, and Assessment phase (Pre-feedback vs. Post-feedback) served as the within subject repeated measures factor. Interaction effects were followed up with simple main effects analyses, comparing Time 1 vs. Time 2 scores for each feedback condition separately. In the second analysis, the planned contrast comparing Failure vs. Neutral feedback was tested using the same analytic approach as that outlined above for the Success vs. Neutral feedback contrast.

\section{Effects for success feedback}

The analysis comparing Time 1 vs. Time 2 scores yielded a significant effect for Time, $F(1,89)=34.70, p<.001$, which was qualified by a significant Time by Condition interaction, $F(1,89)=18.53, p<.001, \eta^{2}=.17$. Subsequent simple effect analyses for both conditions separately revealed a significant increase in state mood in the success condition, $F(1,45)=61.79, p<.001, \eta^{2}=.58$, but no significant change in state mood in the neutral condition, $p>.30$. Taken together, these findings show that the success feedback condition elicited change in state mood in the expected positive direction, whereas the control feedback condition elicited no emotional reactivity.

\section{Effects for failure feedback}

The analysis comparing Time 1 vs. Time 2 scores yielded a main effect for Time, $F(1,85)=12.84, p<.001$, which was qualified by a Time by Condition interaction, $F(1,85)=21.08, p<.001, \eta^{2}=.20$. Subsequent simple effect analyses for both conditions separately revealed a significant decrease in state mood in the failure condition, $F(1,42)=20.83, p<.001, \eta^{2}=.34$, but no significant change in state mood in the neutral condition, $p>.30$ (see above). These findings indicate that the failure feedback condition elicited change in state mood in the expected negative direction.
Do depressive symptoms, social acceptance, or gender moderate change in state mood?

The potential moderating effects of depressive symptoms, social acceptance, and gender on affective change were examined using the regression approach outlined by Aiken and West (1991). Separate hierarchical regression analyses were performed for the success feedback condition and the failure feedback condition, each relative to the control (neutral) feedback condition. In Step 1 of the first analysis, state mood score at Time 2 was regressed on state mood score at Time 1. In Step 2, feedback condition, gender (both dummy coded as 0 or 1 ), social acceptance score (centered), and $\mathrm{CDI}_{t}$ score (centered) were entered. In Step 3, all three two-way interactions were entered, including the $\mathrm{CDI}_{t}$ by Condition interaction term. Finally, the three-way interactions (e.g., Condition by Gender by $\mathrm{CDI}_{\mathrm{t}}$ ) were entered in Step 4.

\section{Moderator effects for success feedback}

Change in mood from pre to post-feedback was significantly predicted by feedback condition (see above). However, neither depressive symptoms, social acceptance score, nor gender moderated the relationship between feedback condition and mood change, as evidenced by non-significant interaction effects $(p$ 's $>.25)$.

\section{Moderator effects for failure feedback}

A similar analytic strategy as reported above for success vs. neutral feedback was employed. Results revealed that change in mood from pre to post-feedback was significantly predicted by feedback condition (see above). Again, none of the three within-person variables examined moderated the relationship between feedback condition and mood change, as evidenced by non-significant interaction effects ( $p$ 's $>.25$ ).

Self-reported feedback preferences: Effects of the feedback manipulation

Self-reported feedback preferences for each of the three conditions are presented in Table 3. Results are reported for the total sample and for the top and bottom third as indexed by children's score on the CDI. Similar to the analyses reported above, we examined feedback preferences in response to success feedback and failure feedback, each relative to the control (neutral) feedback condition.

\section{Effects of success feedback}

As displayed in Table 3, there was no significant effect for Condition. Binominal tests showed that in both 
Table 3 Feedback preferences across conditions broken down by CDI status

\begin{tabular}{|c|c|c|c|c|c|c|}
\hline \multirow[b]{3}{*}{ CDI status } & \multicolumn{6}{|c|}{ Feedback condition } \\
\hline & \multicolumn{2}{|c|}{$\overline{\text { Success }(n=47)}$} & \multicolumn{2}{|c|}{ Neutral $(n=47)$} & \multicolumn{2}{|c|}{ Failure $(n=45)$} \\
\hline & $\begin{array}{l}\text { Preferred } \\
\text { positive }(\%)\end{array}$ & $\begin{array}{l}\text { Preferred } \\
\text { negative }(\%)\end{array}$ & $\begin{array}{l}\text { Preferred } \\
\text { positive }(\%)\end{array}$ & $\begin{array}{l}\text { Preferred } \\
\text { negative }(\%)\end{array}$ & $\begin{array}{l}\text { Preferred } \\
\text { positive }(\%)\end{array}$ & $\begin{array}{l}\text { Preferred } \\
\text { negative }(\%)\end{array}$ \\
\hline Low (Bottom third) CDI $<5$ & 94.5 & 5.5 & 82.4 & 17.6 & 83.3 & 16.7 \\
\hline High (Top third) CDI $>10$ & 88.2 & 11.8 & 93.7 & 6.3 & 35.7 & 64.3 \\
\hline Total sample & 91.5 & 8.5 & 91.5 & 8.5 & 66.7 & 33.3 \\
\hline
\end{tabular}

the success and the neutral condition children preferred significantly more positive feedback than expected by chance $(p$ 's $<.001)$.

\section{Effects of failure feedback}

A Fisher-Exact test revealed a significant effect for condition, $p<.004$. This finding indicates that children randomized to receive a negative peer evaluation outcome, relative to controls, were significantly more inclined to subsequently prefer negatively tuned feedback. However, a binominal test revealed that children in the failure condition still preferred significantly more positive feedback than expected by chance, $p<.04$.

Do depressive symptoms, social acceptance, or gender moderate feedback preferences?

The potential moderating effects of depressive symptoms, social acceptance, and gender on feedback preferences were examined using logistic regression analyses. In these analyses feedback preference (positive vs. negative) served as the binary outcome measure. In Step 1 of the first analysis, state mood at baseline (centered) was entered. In Step 2, feedback condition (success vs. control), gender (both dummy coded as 0 or 1), social acceptance score (centered), and $\mathrm{CDI}_{\mathrm{t}}$ score (centered) were entered. In Step 3, the two-way interaction terms were entered, including the $\mathrm{CDI}_{t}$ by Condition interaction term. Finally, the three-way interaction terms (e.g., Condition by Gender by $\mathrm{CDI}_{\mathrm{t}}$ ) were entered in Step 4. An identical analytic strategy as reported above was used for the failure vs. neutral contrast.

\section{Moderator effects for success feedback}

Feedback preferences were not predicted by either state mood at baseline, gender, condition (see above), $\mathrm{CDI}_{\mathrm{t}}$, or social acceptance score. Moreover, all interaction terms, including the interaction between $\mathrm{CDI}_{\mathrm{t}}$ and condition were not significant $(p$ 's $>.20)$.

\section{Moderator effects for failure feedback}

Feedback preferences were not predicted by state mood at baseline, gender, or social acceptance score. However, we observed a significant effect for condition (see above). Moreover, our findings yielded a significant effect for the interaction between $\mathrm{CDI}_{\mathrm{t}}$ and Condition $(p<.05)$. Subsequent analyses revealed that children higher in depressive symptoms were significantly more likely to prefer negative feedback subsequent to the negative peer evaluation outcome (relative odds $=2.44,95 \% \mathrm{CI}=1.14$ to $5.22, p<.02$ ). In contrast, no significant linkage between depressive symptoms and feedback preferences emerged in the control condition $(p>.30){ }^{1}$

Are the effects of feedback valence on feedback preferences mediated by changes in state mood from pre- to post-feedback?

The proposed mediation model depicted below was examined following Baron and Kenny (1986), who asserted that a variable functions as a mediator when it meets the following three conditions: (a) variations in the level of the independent variable account for variations in the presumed mediator (i.e., change in mood; path A); (b) variation in the level of the presumed mediator account for variations in the dependent variable (i.e., feedback preferences, path B); and (c) after controlling for paths $\mathrm{A}$ and $\mathrm{B}$, a previously significant relation between the independent and dependent variables (i.e., path $\mathrm{C}$ ) is no longer significant, with the strongest demonstration of mediation when path $\mathrm{C}$ becomes zero (Fig. 1).

Our analyses revealed that the second condition for mediation was not met, as evidenced by a non-significant relation

\footnotetext{
${ }^{1}$ We conducted exploratory analyses for the 11 participants (4 success, 4 neutral, and 3 failure) reporting CDI scores of 20 or higher. These analyses revealed that the proportion of children requesting negative feedback were 25,0 , and $100 \%$ for the success, neutral, and failure conditions respectively. Hence, the more severely depressed children in each of the three conditions showed an overall pattern of feedback preferences consistent with the entire sample. However, the preference for negative feedback was more pronounced among the subset of "depressed" children receiving failure feedback $(N=3)$.
} 
Fig. 1 Mediational model of feedback preferences

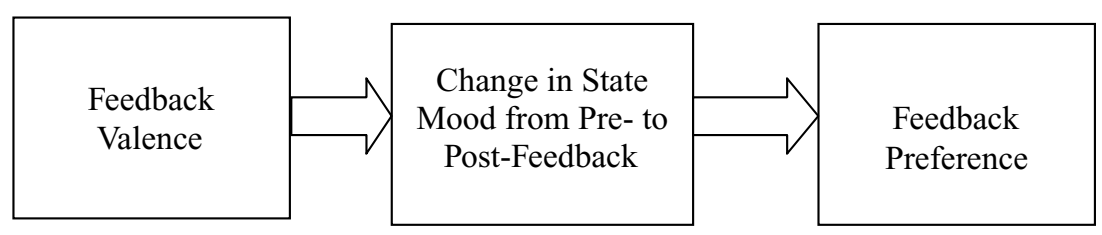

between changes in state mood and feedback preferences. Taken together, our findings show that neither state mood at baseline (see above), nor changes in affect from pre- to post-feedback were significantly associated with children's feedback preferences.

\section{Discussion}

The present study sought to advance our knowledge on how sub-clinical depression in pre-adolescent children is associated with self-reported feedback preferences. To our knowledge, this is the first study to investigate this linkage in response to an experimentally manipulated, ecologically relevant emotion-eliciting event in real time. In so doing, we included both a positive and a negative peer feedback manipulation, along with the assessment of the roles of state mood at baseline, changes in affect from pre- to post-feedback, and actual standing in the peer group. Data on participants' immediate changes in state mood in response to the feedback manipulation revealed that the Survivor contest was successful in eliciting differential affective reactions in the expected direction as a function of feedback valence. Moreover, our debriefing interviews revealed that children were involved in the activity and that none of the participants reported being aware that the feedback they received was bogus. Taken together, these data suggest that the Survivor contest was successful in achieving its major objective of providing a credible and ecologically relevant emotion-eliciting event.

Several interesting findings emerged with respect to the examination of feedback preferences subsequent to receiving a positive (success) and a negative (failure) peer evaluation outcome, each relative to the control feedback condition. For instance, contrary to findings reported by Mischel and colleagues (1973), feedback preferences did not differ as a function of receiving a favorable versus a neutral control peer evaluation outcome. In contrast, relative to the control condition, the negative peer evaluation outcome lead to a significant increase in negatively tuned feedback preferences. However, it should be noted that the negative evaluation outcome merely induced a relative preference for negative feedback, as evidenced by the fact that in all three conditions children sought significantly more positive feedback than expected by chance.

What might account for the finding that the effects of manipulated feedback on subsequent feedback preferences in the present study are at odds with those observed in prior work? One possible explanation may involve the (single and joint) effects of differences in the domain of feedback seeking, the age of the participants, and the specific measures that were employed. For instance, Mischel et al. (1973) provided adult participants with feedback on an intellectual task, and observed that a favorable feedback outcome increased subsequent positive feedback seeking; whereas in the present study pre-adolescent children received feedback on a social task. Another explanation may be that our manipulated peer evaluation outcome differs from the types of manipulations used in other studies examining feedback preferences. It may be that the manipulation employed in the present study may have been more personally relevant (i.e., ego-involving), and hence elicited a different pattern of feedback preferences relative to exposure to less personally relevant feedback (e.g., impressions evaluators had allegedly formed on the basis of participants' displayed nonverbal behavior while delivering a speech; see Swann et al., 1992). Specifically, it seems likely that participants in the present study were more concerned and/or distressed after being rejected based on their personal and physical attributes, relative to participants receiving a negative evaluation based on their non-verbal behavior. Consequently, they may have displayed an increased interest in (preference for) negative feedback, which might be considered more diagnostic and informative on learning why the judges viewed them negatively.

Our findings on the linkages between the valence of the manipulated feedback outcome and subsequent feedback preferences were not consistent with previous work among adults. In a similar vein, our results on the relationship between depressive symptoms and feedback preferences qualify the findings reported by Cassidy et al. (2003). Specifically, in the present study the predictive role of depressive symptoms on subsequent feedback preferences emerged only for children in the negative feedback condition, such that children with higher levels of depressive symptoms displayed a significantly stronger preference for negative feedback. This depression effect was not observed in either the success or control conditions. Interestingly, across conditions we found that children's actual standing in the peer group was not associated with feedback preferences. In this context, it should be noted that in the Joiner et al. (1997) study it was also observed that interest in negative feedback evidenced symptom specificity to depression. 
What might account for the observed effects of depressive symptoms on children's feedback preferences in response to the negative peer evaluation outcome? We considered the possibility that the observed effects were due to the higher levels of depressed mood observed at baseline. However, our findings indicated that this was not the case. Moreover, the observed linkage between depressive symptoms and feedback preferences cannot be explained by change in affect, given that change in affect from pre- to post-feedback did not mediate the single or joint effects of feedback valence and depressive symptoms on feedback preferences. These findings converge with the Joiner et al. (1997) study showing that interest in negative feedback among depressed inpatient children was not associated with the emotional features of depression. We also considered the possibility that self-verification processes might account for the observed linkage between depressive symptoms and feedback preferences. However, our finding that the linkage was present in the failure condition but not in the success or neutral conditions is not in line with self-verification theory, which would predict depression effects across all three conditions. Rather, our findings are more consistent with the formulation put forth by Beck (1967), asserting that depressed (dysphoric) people seek negative feedback only insofar as their negative self-views have been activated by a potent stressful negative event.

Possible implications of our findings deserve mention. The greater tendency for children high in depressive symptoms to seek out negative peer feedback in response to negative peer experiences might contribute to further negative evaluations from peers, and thus serve to maintain or exacerbate depressive symptoms in a cycle similar to that described by Coyne (1976). In line with this reasoning, considerable work has shown both concurrent and prospective linkages between heightened depressive symptoms (depression) in children and peer rejection (Panak \& Garber, 1992), decreased peer interactions (Axelson et al., 2003), and less secure peer attachment (Armsden \& Greenberg, 1987; Armsden, McCauley, Greenberg, Burke, \& Mitchell, 1990). Moreover, in a recent longitudinal study Borelli and Prinstein (2006) observed that a more negative feedback seeking style at baseline was positively associated with more negative perceptions of best friendship criticism at one-year follow-up, and positively associated with increases in depressive symptoms over time. However, this linkage was only found for girls.

Several features of the present study deserve further comment. First, only self-reported feedback preferences were assessed, with no attention given to feedback seeking behavior. Future work should examine children's feedback seeking when they are free to choose how to divide their time between different sources of feedback information. Second, because all significant results are based on children's self-report, it is possible that our findings are partly due to shared method variance. Third, our findings are based on a community sample of children, rather than a clinical sample with a diagnosed mood disorder. Children's mean scores on the CDI suggest that depressive symptoms were relatively modest in magnitude. It is therefore an empirical question to what extent our findings can be generalized to children who meet criteria for major depressive disorder. Finally, this investigation focused only on children's feedback preferences in response to peer evaluation. While peer evaluation has the benefit of being both a potent elicitor of positive and negative affect as well as being ecologically sound, we should not assume that our findings are generalizeable to other relevant domains such as academic failure, interpersonal conflict, and loss or separation.

Notwithstanding these limitations, the results of the present study extend our limited knowledge base on children's feedback preferences in several ways. First, our findings suggest that children respond quite differently with respect to their feedback preferences subsequent to positive or negative evaluations. Second, in line with the Joiner et al. (1997) study, our findings contradict the view that the baseline feeling state of children high in depressive symptoms or manipulations of affect may be involved in governing their preference for more unfavorable feedback. Third, our findings provide evidence to suggest that children displaying elevated depressive symptoms may prefer favorable feedback so long as their negative self-views are not accessed by a potent negative stressful event.

Acknowledgement The authors would like to thank Bill Swann for providing feedback on an earlier draft of the manuscript.

\section{References}

Aiken, L. S., \& West, S. G. (1991). Multiple regression: Testing and Interpreting interactions. Newbury Park, CA: Sage Publications. American Psychological Association. (2000). Diagnostic and statistical manual of mental disorders (5th ed.). Washington, DC: Author.

Armsden, G. C., \& Greenberg, M. T. (1987). The inventory of parent and peer attachment: Individual differences and their relationship to psychological wellbeing in adolescence. Journal of Youth and Adolescence, 16, 427-454.

Armsden, C. G., McCauley, E., Greenberg, M. T., Burke, P. M., \& Mitchell, J. R. (1990). Parent and peer attachment in early adolescent depression. Journal of Abnormal Child Psychology, 18, 683-697.

Axelson, D., Bertocci, M. A., Lewin, D. S., Trubnick, L. S., Birmaher, B., Williamson, D. E., et al. (2003). Measuring mood and complex behavior in natural environments: Use of ecological momentary assessments in pediatric disorders. Journal of Child and Adolescent Psychopharmacology, 13, 253-266.

Baron, R. M., \& Kenny, D. A. (1986). The moderator-mediator variable distinction in social psychological research: Conceptual, strategic, and statistical considerations. Journal of Personality and Social Psychology, 51, 1173-1182. 
Baumeister, R. F., \& Tice, D. M. (1990). Anxiety and social exclusion. Journal of Social and Clinical Psychology, 9, 165-195.

Beck, A. T. (1967). Depression: Clinical, experimental, and theoretical aspects. New York: Harper \& Row.

Beck, A. T., Rush, A. J., Shaw, B. F., \& Emery, G. (1979). Cognitive therapy of depression. New York: Guilford.

Borelli, J. L., \& Prinstein, M. J. (2006). Reciprocal, longitudinal associations among adolescents' negative feedback-seeking, depressive symptoms, and peer relations. Journal of Abnormal Child Psychology, 34, 159-169.

Braet, C., \& Timbremont, B. (2002). Children depression inventory. Dutch version. Lisse: Swets \& Zeitlinger.

Cassidy, J., Ziv, Y., Mehta, T. G., \& Feeney, B. C. (2003). Feedback seeking in children and adolescents: associations with selfperceptions, representations, and depression. Child Development, $74,612-628$

Cohen, P., Cohen, J., Kasen, S., Velez, C. N., Hartmark, C., Johnson, J., et al. (1993). An epidemiological study of disorders in late childhood and adolescence: I. Age- and gender-specific prevalence. Journal of Child Psychology and Psychiatry, 34, $851-867$

Coie, J. D. (1990). Toward a theory of peer rejection. In S. R. Asher \& J. D. Coie (Eds.). Peer rejection in childhood (pp. 365-401). New York: Cambridge University Press.

Compas, B. E. (1997). Depression in children and adolescents. In E. J. Mash \& L. G. Terdal (Eds.), Assessment of childhood disorders (pp. 197-229). New York: Guilford.

Costello, E. J., Angold, A., \& Keeler, G. P. (1999). Adolescent outcomes of childhood disorders: The consequences of severity and impairment. Journal of the American Academy of Child and Adolescent Psychiatry, 38, 121-128.

Coyne, J. C. (1976). Depression and the response of others. Journal of Abnormal Psychology, 85, 186-193.

Ellis, A. (1977). The basic clinical theory of rational-emotive therapy. In A. Ellis \& R. Grieger (Eds.), Handbook of rational-emotive therapy(pp. 84-134). New York: Springer.

Gross, J. J. (1998). Antecedent- and response-focused emotion regulation: Divergent consequences for experience, expression, and physiology. Journal of Personality and Social Psychology, 74, 224-237.

Grusec, J. E., \& Lytton, H. (1988). Social development. New York: Springer-Verlag.

Hammen, C., \& Rudolph, K. D. (1996). Childhood depression. In E. J. Mash \& R. A. Barkley (Eds.), Child psychopathology (pp. 153195). New York: Guilford.

Harter, S. (1998). The development of self-representations. In W. Damon (Series Ed.) and N. Eisenberg (Vol. Ed.), Handbook of child psychology, Vol. III: Social, emotional, and personality development (5th ed., pp. 563-617). New York: Wiley.

Hartup, W. W. (1996). The company they keep: Friendships and their developmental significance. Child Development, 97, 1-13.

Hay, D. F., Payne, A., \& Chadwick, A. (2004). Peer relations in childhood. Journal of Child Psychology and Psychiatry, 45, 84-108.

Joiner, T. E., Jr., Katz, J., \& Lew, A. S. (1997). Self-verification and depression among youth psychiatric inpatients. Journal of Abnormal Psychology, 106, 608-618.

Kovacs, M. (1981). Rating scales to assess depression in school-aged children. Acta Paedo Psychiatra, 46, 305-315.

Kovacs, M. (1992). Children's depression inventory manual. North Tonawanda, NY: MultiHealth Systems.

Leary, M. R., Tambor, E. S., Terdal, S. J., \& Downs, D. L. (1995). Self-esteem as an interpersonal monitor: The sociometer hypothesis. Journal of Personality and Social Psychology, 68, $518-530$

Lewinsohn, P. M., Rohde, P., Klein, D. N., \& Seeley, J. R. (1999). Natural course of adolescent major depressive disorder: I. Continuity into young adulthood. Journal of the American Academy of Child and Adolescent Psychiatry, 38, 56-63.

Mischel, W., Ebbesen, W. B., \& Zeiss, A. R. (1973). Selective attention to self-situational and dispositional determinants. Journal of Personality and Social Psychology, 27, 129-142.

Murray, C. J. L., \& Lopez, A. D. (1996). World health organization monograph. Geneva: World Health Organization.

Nolan, S. A., Flynn, C., \& Garber, J. (2003). Prospective relations between rejection and depression in young adolescents. Journal of Personality and Social Psychology, 85, 745-755.

Newcomb, A. F., Bukowski, W. M., \& Pattee, L. (1993). Children's peer relations: A meta-analytic review of popular, rejected, neglected, controversial, and average sociometric Status. Psychological Bulletin, 113, 99-128.

Nolen-Hoeksema, S., Girgus, J. S., \& Seligman, S. E. P. (1992). Predictors and consequences of childhood depressive symptoms: A fiveyear longitudinal study. Journal of Abnormal Psychology, 101, 405-422.

Panak, W. F., \& Garber, J. (1992). Role of aggression, rejection, and attributions in the prediction of depression in children. Development and Psychopathology, 4, 145-165.

Petersen, A. C., Sarigiani, P. A., \& Kennedy, R. E. (1991). Adolescent depression: Why more girls? Journal of Youth and Adolescence, 20, 247-271.

Reijntjes, A., Stegge, H., Meerum Terwogt, M., Kamphuis, J. H., \& Telch, M. J. (2006). Children's coping with in vivo peer rejection: An experimental investigation. Journal of Abnormal Child Psychology, 34, 877-889.

Rubin, K. H., Bukowski, W., \& Parker, J. G. (1998). Peer interactions, relationships, and groups. In W. Damon (Series Ed.) and N. Eisenberg (Vol. Ed.), Handbook of child psychology, Vol. III: Social, emotional, and personality development (5th ed., pp. 619700). New York: Wiley.

Saylor, C. A., Finch, A. J., Spirito, A., \& Bennett, B. (1984). The child depression inventory: A systematic evaluation of psychometric properties. Journal of Consulting and Clinical Psychology, 52, 955-967.

Smucker, M. R., Craighead, W. E., Craighead, L. W., \& Green, B. J. (1986). Normative and reliability data for the children's depression inventory. Journal of Abnormal Child Psychology, 14, 25-39.

Swann, W. B., Jr. (1983). Self-verification: Bringing social reality into harmony with the self. In J. Suls \& A. G. Greenwald (Eds.). Psychological perspectives on the self (Vol. 2, pp. 33-66). Hillsdale, NJ: Erlbaum.

Swann, W. B., Jr. (1990). To be adored or to be known: The interplay between self-enhancement and self-verification. In R. M. Sorrentino \& E. T. Higgens (Eds.), Foundations of social behavior (Vol. 2, pp. 408-448). New York: Guilford Press.

Swann, W. B., Jr., Pelham, B., \& Krull, D. (1989). Agreeable fancy or disagreeable truth? Reconciling self-enhancement and selfverification. Journal of Personality and Social Psychology, 57, 782-791.

Swann, W. B., Jr., Rentfrow, P., \& Guinn, J. (2002). Self-verification: The search for coherence. In M. Leary \& J. Tagney (Eds.), Handbook of self and identity (pp. 367-383). New York: Guilford Press.

Swann, W. B., Jr., Wenzlaff, R. M., Krull, D. S., \& Pelham, B. W. (1992). Allure of negative feedback: Self-verification strivings among depressed persons. Journal of Abnormal Psychology, 101, 293-306.

Swann, W. B., Jr., Wenzlaff, R. M., \& Tafarodi, R. W. (1992). Depression and the search for negative evaluations: More evidence of the role of self-verification strivings. Journal of Abnormal Psychology, 101, 314-317. 